\title{
Motivational interviewing to enhance nicotine patch treatment for smoking cessation among homeless smokers: a randomized controlled trial
}

\author{
Kolawole S. Okuyemi ${ }^{1,2,3,4}$, Kate Goldade ${ }^{1,2}$, Guy-Lucien Whembolua ${ }^{1,2,3}$, Janet L. Thomas ${ }^{2,3,4,5}$, \\ Sara Eischen ${ }^{1,2}$, Barrett Sewali ${ }^{1,2}$, Hongfei Guo ${ }^{7}$, John E. Connett ${ }^{7}$, Jon Grant ${ }^{6}$, \\ Jasjit S. Ahluwalia ${ }^{2,3,4,5}$, Ken Resnicow ${ }^{8}$, Greg Owen', Lillian Gelberg ${ }^{10}$ \& Don Des Jarlais ${ }^{\prime \prime}$ \\ Department of Family Medicine and Community Health, University of Minnesota, Minneapolis, MN, USA,' Program in Health Disparities Research, University Of \\ Minnesota, Minneapolis, MN, USA, ${ }^{2}$ Center for Health Equity, University of Minnesota, Minneapolis, MN, USA, ${ }^{3}$ Masonic Cancer Center, University Of Minnesota, \\ Minneapolis, MN, USA, ${ }^{4}$ Department of Medicine, University of Minnesota, Minneapolis, MN, USA, ${ }^{5}$ Department of Psychiatry, University of Minnesota, \\ Minneapolis, MN, USA, ${ }^{6}$ Division of Biostatistics, School of Public Health, Clinical and Translational Institute, University of Minnesota, Minneapolis, MN, USA, \\ Department of Health Behavior and Health Education, University of Michigan, Ann Arbor, MI, USA, ${ }^{8}$ Wilder Foundation, Saint Paul, MN, USA, ${ }^{9}$ Department of \\ Family Medicine, David Geffen School of Medicine at UCLA, Los Angeles, CA, USA ${ }^{10}$ and Baron Edmond de Rothschild Chemical Dependency Institute, Beth Israel \\ Medical Center, Albert Einstein College of Medicine, New York, NY, USA'I
}

\begin{abstract}
Aims To assess the effects of adding motivational interviewing (MI) counseling to nicotine patch for smoking cessation among homeless smokers. Design Two-group randomized controlled trial with 26-week follow-up. Participants and setting A total of 430 homeless smokers from emergency shelters and transitional housing units in Minneapolis/St Paul, Minnesota, USA. Intervention and measurements All participants received 8-week treatment of 21-mg nicotine patch. In addition, participants in the intervention group received six individual sessions of MI counseling which aimed to increase adherence to nicotine patches and to motivate cessation. Participants in the standard care control group received one session of brief advice to quit smoking. Primary outcome was 7-day abstinence from cigarette smoking at 26 weeks, as validated by exhaled carbon monoxide and salivary cotinine. Findings Using intention-to-treat analysis, verified 7-day abstinence rate at week 26 for the intervention group was non-significantly higher than for the control group $(9.3 \%$ versus $5.6 \%, P=0.15)$. Among participants who did not quit smoking, reduction in number of cigarettes from baseline to week 26 was equally high in both study groups $(-13.7 \pm 11.9$ for MI versus $-13.5 \pm 16.2$ for standard care). Conclusions Adding motivational interviewing counseling to nicotine patch did not increase smoking rate significantly at 26-week follow-up for homeless smokers.
\end{abstract}

Keywords Brief advice, homeless, motivational interviewing, nicotine patch, smoking cessation.

Correspondence to: Kolawole S. Okuyemi, Department of Family Medicine and Community Health, 717 Delaware Street SE. Ste. 166, Minneapolis, MN 55414, USA. E-mail: kokuyemi@umn.edu

Submitted 15 June 2012; initial review completed 6 September 2012; final version accepted 29 January 2013

\section{INTRODUCTION}

The prevalence of cigarette smoking among homeless adults remains an alarming $70-80 \%$ or greater $[1,2]$, which is two to three times that of the general adult population in the United States.

Because homeless individuals are faced with meeting competing basic survival needs such as finding food and shelter, it is often assumed that smoking cessation is not a priority for this population. However, recent crosssectional surveys showed that homeless smokers reported a similar level of interest in smoking cessation and quit attempts compared to the general population of smokers $[3,4]$. Nicotine replacement alone or in combination with other treatments was the most preferred treatment $(42.2 \%)$, followed by counseling alone or in combination (24.6\%)

Homeless smokers face multiple barriers to accessing and adhering to treatments [5], such as the daily need to find food, clothing and shelter as well as practical limits on accessing and storing medicines. Furthermore, high rates of psychiatric and other substance abuse comorbidity conditions [6] within homeless populations could create additional challenges to adherence to 
smoking cessation treatment and ultimately to smoking cessation.

While studies on motivational interviewing (MI) for smoking cessation have yielded mixed results, a recent meta-analysis ( $n=23$ studies) suggests that MI outperformed comparison conditions significantly at long-term follow-up points [7]. Also, MI has been shown to improve treatment adherence and retention [8]. In a pilot study of nicotine patch use among homeless smokers, MI was shown to be a feasible and acceptable intervention; however, MI was not used to address adherence in that study [9]. To date, there are no controlled trials of interventions to improve adherence to self-administered medications that target homeless people specifically. To address this gap we conducted a smoking cessation randomized clinical trial (RCT) among smokers experiencing homelessness, called Power To Quit (PTQ). We tested the hypothesis that MI addressing smoking and nicotine replacement therapy (NRT) adherence will result in higher quit rates among homeless smokers compared to standard care. The current paper describes the smoking cessation (primary) and NRT adherence (secondary) outcomes of the study. Understanding the effectiveness of smoking cessation treatment for this underserved population will assist researchers and health-care providers in developing and implementing smoking cessation interventions for homeless and other vulnerable populations.

\section{METHODS}

\section{Study design}

This study was a community-based RCT of 430 homeless adult cigarette smokers that assessed the effectiveness of MI for smoking cessation. Participants were randomized to either the intervention arm (nicotine patch $+\mathrm{MI}$ ) or the control arm (nicotine patch + standard care). At baseline, participants in both groups received a 2-week supply of 21-mg nicotine patches, and every 2 weeks they received an additional 2-week supply of $21 \mathrm{mg}$ nicotine patches. Participants randomized to the intervention arm also received six individual MI counseling sessions, each lasting 15-20 minutes, while participants randomized to the standard care arm received a one-time brief (10-15 minutes) advice session to quit smoking. Participants provided written informed consent before they were enrolled into the study. The study procedures, which have been published elsewhere [10,11], were approved and monitored by the University of Minnesota's Institutional Review Board.

\section{Participant recruitment and randomization}

Recruitment occurred from May 2009 to August 2010 at a total of eight homeless shelters in Minneapolis/St Paul,
Minnesota. Recruitment was conducted at health fairs and via staff informational sessions and posted flyers at the study sites. Study eligibility criteria included being currently homeless and having lived in the Twin Cities for $\geq 6$ months, having smoked at least one cigarette per day in the past 7 days and at least 100 cigarettes in their life-time, aged $\geq 18$ years, and willing to use nicotine patches for 8 weeks and participate in counseling sessions. Participants were classified as homeless based upon the Stewart B. McKinney Act passed by the US congress in 1987, in which homelessness was defined as anyone lacking 'a fixed, regular and adequate nighttime residence' or anyone staying at 'a supervised publicly or privately operated shelter designed to provide temporary living accommodations, transitional housing, or other supportive housing program or a public or private place not meant for human habitation' [12]. Smoking status was confirmed with an exhaled carbon monoxide (CO) monitor using a cut-off of 5 parts per million (p.p.m.). Exclusion criteria included: pregnancy, use of another tobacco cessation aid in the previous 30 days, severe cognitive impairment, suicidal ideation in the last 14 days, a major medical condition within the prior month or scoring $>5$ on items assessing psychotic symptoms from the nine-item Mini International Neuropsychiatric Interview (MINI) [13].

At the baseline visit, pre-assigned randomization numbers prepared by the study statistician determined into which study arm the participant would be enrolled. The assignment to MI versus standard care was not blinded to participants. Sequential enrollment continued until a total of 430 participants were randomized into the study.

\section{Treatment period}

Eligible participants were scheduled for the baseline appointment 7-10 days after the initial contact. At the baseline visit participants were assigned randomly to either the MI intervention arm or to the standard care control arm. All participants received a health educational resource called 'The Power to Quit: A Quit Smoking Guide', a 23-page guide developed by the project investigators. The guide included messages on the health risks of smoking, common reasons for smoking and cognitive exercises to improve self-directed quit attempts.

\section{Intervention components}

Motivational interviewing (MI)

Participants randomized to the MI intervention arm received six individual MI counseling sessions, each lasting 15-20 minutes. The MI counseling sessions were conducted by trained counselors and occurred at baseline 
and follow-up at weeks 1, 2, 4, 6 and 8. The focus of the MI sessions was encouraging cessation and NRT adherence. Although MI has been used typically to build motivation to quit [7], we also applied the principles and strategies to encourage adherence to the patch.

\section{Standard care}

Participants in the standard care control condition received a one-time session of brief advice to quit smoking lasting approximately 10-15 minutes and delivered by trained study counselors [10]. Topics covered in the standard care session included smoking history, current smoking, direct advice about the health risks of smoking and the health benefits of quitting, affirmation of the participant's decision to quit, an assessment of preparedness to quit and addressing strategies for coping with smoking cues.

\section{Retention}

To minimize attrition, study staff made reminder calls to participants during the week prior to each appointment, both pending and missed, until the window for completing appointments closed. Calls were placed from the project office and made either to each participant's cellphone or to the shelter identified as the most recent nighttime residence in the participant's file. At each of the 15 visits, participants received incentives. For participants who attended all 15 sessions, the monetary incentives totaled \$275 over 6 months $[10,11]$.

\section{Measures}

All questionnaire items were read to, or along with, the participants by trained research assistants that included master's level public health students, medical students or community mobilizers. Community mobilizers were individuals who had experienced homelessness either themselves or with a family member. At the baseline visit, we assessed demographic and smoking behaviors, psychosocial variables, environmental factors and biological measurements. Demographic variables included age, ethnicity, gender, income, education level, marital status and employment status and homelessness history, including duration and type of homelessness. Psychosocial variables included social support $[14,15]$ and self-efficacy to refrain from smoking using the Smoking Self-Efficacy Questionnaire (SEQ-12) [16]. Psychiatric comorbidities of depression and anxiety were assessed with the fouritem Rost-Burnham screener for depression [17], the patient health questionnaire (PHQ-9) for depression [18], the four-item perceived stress scale for stress in past 30 days [19] and the MINI generalized anxiety disorder assessment [13]. Further, study participants were asked questions about life-time drug treatment history and drug and alcohol use and dependence [17]. Adherence to nicotine patch use was measured by direct observation by study staff at weeks 2, 4, 6 and 8. Participants were asked if they were wearing the patch; for those who answered in the affirmative, study staff then asked to see the patch. Motivation and confidence for adherence to NRT patch was assessed with the Motivation/Confidence to Adhere Scale [20], which is a five-item scale with score range of 1-10 for each item and reflects participants' level of commitment, desire, need and readiness to adhere to smoking cessation. Higher totals indicate higher levels of motivation for adherence (Cronbach's alpha =0.84); SelfEfficacy to Adhere [21] is a modified 10-item Adult AIDS Clinical Trials Group (AACTG) measure which asks participants to indicate their level of confidence in performing specific adherence tasks relating to treatment. Responses range from 0 (cannot do at all) to 10 (certain I can do). Higher scores indicate higher adherence self-efficacy.

The primary outcome was biochemically verified self-reported 7-day point prevalence abstinence from smoking assessed at week 26 post-randomization, defined as having smoked no cigarettes (not even a puff) during the previous 7 days. Those who self-reported abstinence were verified using an expired carbon monoxide ( $\leq 10$ p.p.m.) test. Salivary cotinine testing was performed if the expired $\mathrm{CO}$ was greater than 10 p.p.m. for those who self-reported abstinence. A cut-off of $\leq 20 \mathrm{ng} / \mathrm{ml}$ for salivary cotinine was used to verify abstinence. The secondary outcome was adherence to the nicotine patch, measured by direct observation at in-person appointments during the treatment period.

\section{Analysis}

The sample size was determined a priori assuming a twotailed type I error of 0.05 , a power of at least $80 \%$ and a week 26 biochemically verified quit rate of $18 \%$ and $8 \%$ for MI intervention and standard care conditions, respectively, based on previous research [9]. The primary analysis was a Yates-corrected $\chi^{2}$ test of the difference between the proportions quit in the two groups. With these assumptions, using the $\chi^{2}$ test we needed 214 participants per study arm. With the final sample of 430 participants achieved, we had $83 \%$ power (at a $5 \%$ significance level) to detect statistically significant main effects. Following intention-to-treat analyses, participants who did not attend the 26-week visits were assumed to be smokers. We also compared CO-verified repeated 7-day abstinence at weeks 8 and 26 using the $\chi^{2}$ test as a secondary outcome measure. The repeated point prevalence abstinence was defined as participants who 
self-reported and verified by $\mathrm{CO}$ or cotinine that they were abstinent both at weeks 8 and 26. All the other participants were treated as smokers. We also performed longitudinal analysis using repeated-measures logistic regression with generalized estimating equations for the CO-verified abstinence at weeks $1,2,4,6,8$ and 26, including time (continuous) and intervention group as predictors, using PROC GENMOD in SAS version 9.2 (SAS Institute Inc., 2009 \#6990).

\section{RESULTS}

Of the 839 individuals screened for study eligibility, 568 were eligible and 430 were randomized, 216 to the MI intervention and 214 to the control group (Fig. 1). Eligible participants who returned for randomization were older and more likely to have a telephone number compared to eligible participants who were not enrolled into the study. Of the 430 enrolled, $76.1 \%$ completed their week 8 visit (end of treatment) and $75.4 \%$ completed the final week 26 visit. There were no significant differences in attrition rates (Table 4 ) between the two study groups.
There were no significant differences in baseline characteristics of participants between treatment groups (Table 1). Participants' mean age was 44 years and the majority were male; African American or white; unemployed; high school graduate or equivalent; with a monthly income of less than US\$400. Nearly two-thirds reported often sleeping in emergency shelters and 15\% slept in transitional housing in the past 6 months. Participants smoked about a pack of cigarettes a day and $87 \%$ smoked their first cigarette of the day within 30 minutes of awakening. More than $80 \%$ of the sample screened positive for life-time history of drug abuse or dependence. Self-reported and verified 7-day point prevalence abstinence rates for the MI and control study groups at various assessment points are shown in Table 2.

Using intention-to-treat analysis, 7-day verified smoking abstinence rates at week 8 were $9.3 \%$ versus $8.9 \%(P=0.89)$ and at week 26 were $9.3 \%$ versus $5.6 \%$ $(P=0.15)$ for the intervention and control groups, respectively. The repeated point prevalence abstinence rate was $3.24 \%$ for the MI group and $1.40 \%$ for the standard care group (Fisher's exact test $P=0.338$ ). We

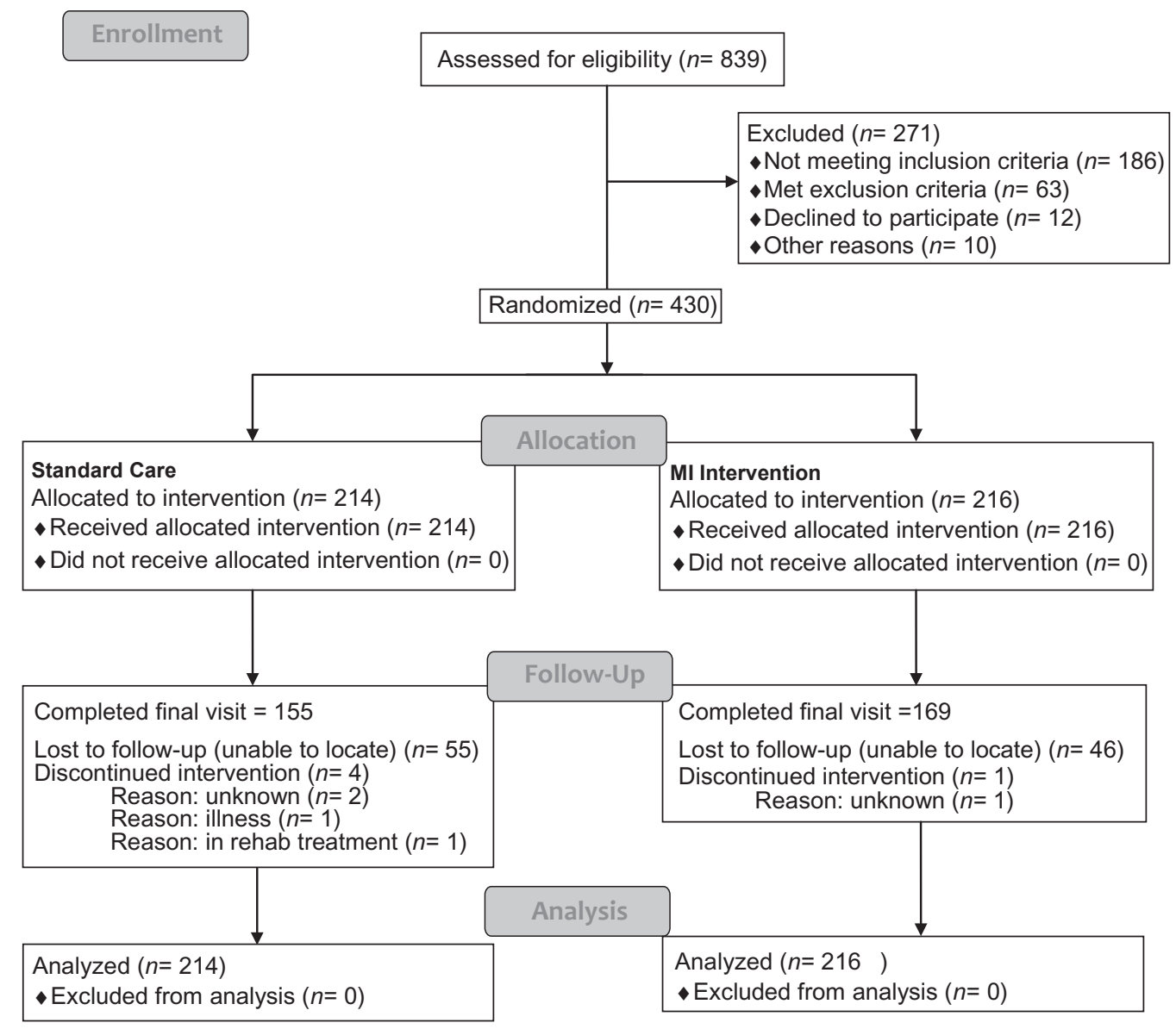

Figure I Consolidated Standards of Reporting Trials (CONSORT) [22] flow diagram for the study 
Table 1 Baseline characteristics of 430 study participants enrolled into the Power to Quit (PTQ) study.

\begin{tabular}{|c|c|c|c|c|c|}
\hline & \multirow{2}{*}{$\begin{array}{l}\text { Total } \\
n=430\end{array}$} & \multicolumn{2}{|c|}{$\begin{array}{l}\text { Motivational interviewing arm } \\
n=216\end{array}$} & \multicolumn{2}{|c|}{$\begin{array}{l}\text { Standard care arm } \\
n=214\end{array}$} \\
\hline & & Mean (SD) & $n$ & Mean (SD) & $n$ \\
\hline \multicolumn{6}{|l|}{ Demographic variables } \\
\hline Age, mean \pm SD, years & $44.4(9.9)$ & $44.5(9.7)$ & 216 & $44.2(10.1)$ & 214 \\
\hline Male, $n(\%)$ & $321(74.7)$ & $158(73.1)$ & 216 & $163(76.2)$ & 214 \\
\hline \multicolumn{6}{|l|}{ Race/ethnicity, $n(\%)$} \\
\hline African American/black & $242(56.3)$ & $130(60.2)$ & 216 & $112(52.3)$ & 214 \\
\hline White, non-Hispanic & $153(35.6)$ & $69(31.9)$ & & $84(39.3)$ & \\
\hline Hispanic/Latino & $10(2.3)$ & $5(2.3)$ & & $5(2.3)$ & \\
\hline Native American/Alaska Native & $10(2.3)$ & $5(2.3)$ & & $5(2.3)$ & \\
\hline Other & $14(2.3)$ & $7(3.3)$ & & $7(3.3)$ & \\
\hline Monthly family income $<\$ 400, n(\%)$ & $273(63.5)$ & $140(64.8)$ & 216 & $133(62.1)$ & 214 \\
\hline Education $\geq$ high school, $n(\%)$ & $330(76.8)$ & $166(76.9)$ & 216 & $164(76.6)$ & 214 \\
\hline BMI, mean (SD) & $30.1(7.6)$ & $30.3(7.8)$ & 215 & $30.0(7.5)$ & 211 \\
\hline \multicolumn{6}{|l|}{ Psychosocial variables } \\
\hline Depression (PHQ9, in past 2 weeks), mean (SD) & $8.5(6.4)$ & $8.8(6.7)$ & 216 & $8.1(6.1)$ & 212 \\
\hline PHQ9 $\geq 10$ in past 2 weeks, $n(\%)$ & $148(34.6)$ & $92(42.5)$ & 216 & $81(38.2)$ & 212 \\
\hline Stress (PSS-4, in past 30 days), mean (SD) & $8.4(2.3)$ & $8.5(2.5)$ & 215 & $8.3(2.1)$ & 213 \\
\hline \multicolumn{6}{|l|}{ Tobacco-related variables } \\
\hline Serum cotinine in ng/ml, mean (SD) & $213.7(159.0)$ & $229.2(179.9)$ & 204 & $198.3(133.8)$ & 205 \\
\hline Exhaled carbon monoxide in p.p.m., mean (SD) ${ }^{\mathrm{a}}$ & $15.6(9.0)$ & $15.0(8.3)$ & 202 & $16.2(9.65)$ & 207 \\
\hline Cigarettes per day, mean (SD) & $19.3(13.7)$ & $19.1(11.1)$ & 215 & $19.4(16.0)$ & 212 \\
\hline Time to first cigarette, $\leq 30$ minutes, $n(\%)$ & $374(87.0)$ & $188(87.0)$ & 216 & $186(87.0)$ & 270 \\
\hline Smoke menthol cigarettes, $n(\%)$ & $268(62.6)$ & $138(64.2)$ & 216 & $130(61.0)$ & 214 \\
\hline $\begin{array}{l}\text { Number of } 24 \text { hours quit attempts in the past year, } \\
\text { mean (SD) }\end{array}$ & $2.5(5.2)$ & $2.5(5.3)$ & 212 & $2.6(5.1)$ & 212 \\
\hline Age started smoking regularly, mean (SD) & $16.2(5.9)$ & $16.3(6.0)$ & 215 & $16.1(5.7)$ & 214 \\
\hline Motivation to quit, mean (SD) & $9.1(1.6)$ & $9.0(1.8)$ & 216 & $9.1(1.5)$ & 214 \\
\hline Confidence to quit, mean (SD) & $7.3(2.4)$ & $7.3(2.4)$ & 216 & $7.3(2.5)$ & 214 \\
\hline \multicolumn{6}{|l|}{ Substance abuse variables } \\
\hline $\begin{array}{l}\text { Ever used illicit drug }{ }^{\mathrm{a}} \text { more than } 5 \text { times in life-time, } \\
\quad n(\%)\end{array}$ & $355(82.8)$ & $182(84.3)$ & 216 & $173(81.2)$ & 213 \\
\hline $\begin{array}{l}\text { Ever needed larger amount of illicit drugs to get an } \\
\text { effect, } n(\%)\end{array}$ & $170(39.6)$ & $80(37.0)$ & 216 & $90(42.3)$ & 213 \\
\hline $\begin{array}{l}\text { Ever had emotional or psychological problems from } \\
\text { using illicit drugs, } n(\%)\end{array}$ & $140(32.6)$ & $65(30.1)$ & 216 & $75(35.2)$ & 213 \\
\hline Ever thought you were an excessive drinker, $n(\%)$ & $195(45.5)$ & $95(44.0)$ & 216 & $100(46.9)$ & 213 \\
\hline Ever drank one-fifth of liquor in one day, $n(\%)$ & $179(41.7)$ & $90(41.7)$ & 216 & $89(41.8)$ & 213 \\
\hline $\begin{array}{l}\text { Ever drank } 7 \text { or more alcoholic drinks daily for } 2 \\
\text { weeks, } n(\%)\end{array}$ & $174(40.7)$ & $83(38.6)$ & 216 & $91(42.9)$ & 213 \\
\hline
\end{tabular}

BMI = body mass index; MI = motivational interviewing; SC = standard care; SD = standard deviation; PHQ9 = Patient Health Questionaire-9 Depression Scale; PSS-4 = Perceived Stress Scale, four items; p.p.m. = parts per million. 'aist of drugs included marijuana (hashish, pot, grass); amphetamines (stimulants, uppers, speed); barbiturates (sedatives, downers, sleeping pills, Seconal, Quaaludes); tranquilizers (Valium, Librium); cocaine (coke, crack); heroin; opiates (codeine, Demerol, morphine, methadone, Darvon, opium), psychedelics [lysergic acid diethylamide (LSD), mescaline, peyote, psilocybin, dimethyltryptamine (DMT), phencyclidine (PCP)].

used repeated-measures logistic regression with generalized estimating equations (Fig. 2) for the CO-verified abstinence at weeks $1,2,4,6,8$ and 26, while treating those lost to follow-up as smokers, and included time (continuous) and intervention group as predictors. This yielded an odds ratio for the MI versus standard care group of 1.33 [95\% confidence interval (CI): 0.88, 2.02; $P=0.17]$. If those lost to follow-up were treated as missing, the odds ratio for the MI versus SC group was
1.40 (95\% CI: 0.93, 2.11; $P=0.11)$. Among participants that did not quit smoking, reduction in number of cigarettes from baseline to week 26 was equally high in both study groups $(-13.7 \pm 11.9$ for MI versus $-13.5 \pm 16.2$ for standard care).

Table 3 shows results of various measures of adherence. Motivation for adherence scores at week 6 were marginally higher for participants in the intervention group than those in the control group $(45.8 \pm 6.9$ for MI 
versus $44.4 \pm 7.4$ for control, $P=0.08)$. Table 3 also shows results of 'patch checks', i.e. the proportion of participants who had their nicotine patches on at various study visits. There were no differences between study groups in the proportion of participants who had their

Table 2 Self-report and biochemically verified 7-day pointprevalence abstinence rates of 430 study participants enrolled into the Power to Quit (PTQ) study. ${ }^{\mathrm{a}}$

\begin{tabular}{llll}
\hline & MI & Standard care & P-value \\
\hline Self-report & & & \\
$\quad$ Quit at week 8, $n(\%)$ & $33(15.28 \%)$ & $26(12.15 \%)$ & 0.350 \\
$\quad$ Quit at week 26, $n(\%)$ & $36(16.67 \%)$ & $25(11.68 \%)$ & 0.140 \\
Verified & & & \\
$\quad$ Quit at week 8, $n(\%)$ & $20(9.26 \%)$ & $19(8.88 \%)$ & 0.890 \\
Quit at week 26 n(\%) & $20(9.26 \%)$ & $12(5.61 \%)$ & 0.150 \\
\hline
\end{tabular}

aThose lost to follow-up were treated as smokers; ${ }^{\mathrm{b}}$ carbon monoxide $(\leq 10$ parts per million) or cotinine $(\leq 20 \mathrm{ng} / \mathrm{ml})$ verified. $\mathrm{MI}=$ motivational interviewing.

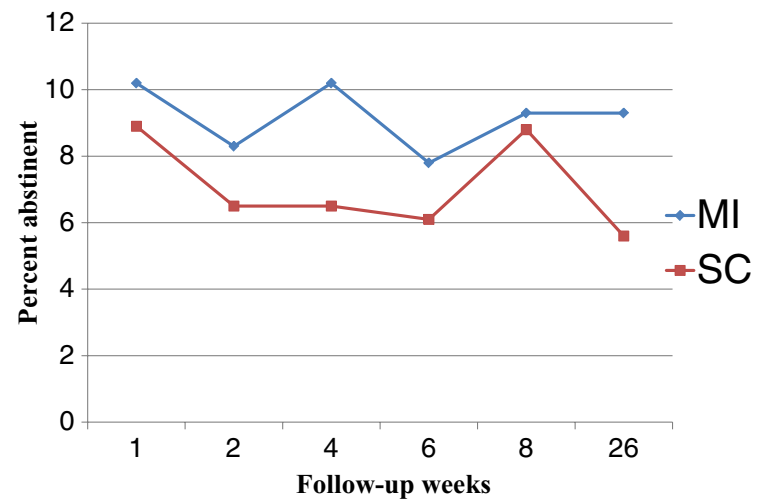

Figure 2 Verified abstinence by time nicotine patches on at various study visits. Table 4 shows the attendance for various study contact points.

\section{DISCUSSION}

Results from this study show that verified quit rates at weeks 8 and 26 for MI were not significantly better than those for standard care. Although the quit rates for MI were consistently higher at all study time-points, the magnitude of the effects was small.

The $9.3 \%$ verified quit rate at week 26 is comparable to findings from a cluster-randomized trial that tested

Table 4 Summary of attendance at study visits of 430 study participants enrolled into the Power to Quit (PTQ) study.

\begin{tabular}{|c|c|c|c|c|}
\hline \multirow{3}{*}{$\begin{array}{l}\text { Study visit } \\
\text { time-points }\end{array}$} & \multicolumn{4}{|c|}{ Study visit completed } \\
\hline & \multicolumn{2}{|c|}{$S C(n=214)$} & \multicolumn{2}{|c|}{$M I(n=216)$} \\
\hline & $n$ & $\%$ & $n$ & $\%$ \\
\hline Week 1 & 191 & 89.3 & 189 & 87.5 \\
\hline Week 2 & 190 & 88.8 & 172 & 79.6 \\
\hline Week 4 & 184 & 86.0 & 174 & 80.6 \\
\hline Week 6 & 171 & 79.9 & 159 & 73.6 \\
\hline Week 8 & 168 & 78.5 & 162 & 75.0 \\
\hline Week 10 & 146 & 68.2 & 145 & 67.1 \\
\hline Week 12 & 143 & 66.8 & 155 & 71.8 \\
\hline Week 14 & 140 & 65.4 & 145 & 67.1 \\
\hline Week 16 & 137 & 64.0 & 143 & 66.2 \\
\hline Week 18 & 142 & 66.4 & 146 & 67.6 \\
\hline Week 20 & 136 & 63.6 & 146 & 67.6 \\
\hline Week 22 & 139 & 65.0 & 155 & 71.8 \\
\hline Week 24 & 141 & 65.9 & 156 & 72.2 \\
\hline Week 26 & 155 & 72.4 & 169 & 78.2 \\
\hline
\end{tabular}

$\mathrm{SC}=$ standard care $; \mathrm{MI}=$ motivational interviewing.

Table 3 Adherence measures of 430 study participants enrolled into the Power to Quit (PTQ) study.

\begin{tabular}{|c|c|c|c|c|}
\hline Variables & $\begin{array}{l}\text { Total } \\
(n=430)\end{array}$ & $\begin{array}{l}\text { MI } \\
(n=216)\end{array}$ & $\begin{array}{l}\text { Standard care } \\
(n=214)\end{array}$ & P-value \\
\hline Baseline motivation to adhere, mean (SD) & $45.4(6.5)$ & $45.4(6.3)$ & $45.3(6.7)$ & 0.77 \\
\hline Week 6 motivation to adhere, mean (SD) & $45.1(7.3)$ & $45.8(7.0)$ & $44.4(7.5)$ & 0.08 \\
\hline $\begin{array}{l}\text { Motivation to adhere change in scores from baseline to week } 6 \text {, } \\
\text { mean (SD) }\end{array}$ & $0.02(8.2)$ & $0.4(8.4)$ & $-0.4(8.1)$ & 0.40 \\
\hline Baseline self-efficacy to adhere, mean (SD) & $78.4(17.6)$ & $78.2(18.0)$ & $78.7(17.1)$ & 0.76 \\
\hline Week 6 self-efficacy to adhere, mean (SD) & $84.1(18.3)$ & $85.4(19.1)$ & $82.9(17.5)$ & 0.22 \\
\hline $\begin{array}{l}\text { Self-efficacy to adhere change in scores from baseline to week } 6 \text {, } \\
\text { mean (SD) }\end{array}$ & $5.7(20.8)$ & $5.7(22.5)$ & $5.7(19.2)$ & 0.99 \\
\hline \multicolumn{5}{|l|}{ Had nicotine patch on at visit ('patch check'), \% yes } \\
\hline Week 1 & 52.8 & 49.1 & 56.5 & 0.12 \\
\hline Week 2 & 52.6 & 49.1 & 56.1 & 0.15 \\
\hline Week 4 & 44.7 & 46.8 & 42.5 & 0.38 \\
\hline Week 6 & 38.6 & 40.7 & 36.5 & 0.36 \\
\hline Week 8 & 33.7 & 33.8 & 33.7 & 0.97 \\
\hline
\end{tabular}


nicotine gum plus five MI sessions for smoking cessation in 20 low-income housing developments $(n=173)$ [23]. For that study, biochemically verified 7-day abstinence rates were $6.1 \%$ versus $5.6 \%$ at week 8 and $7.6 \%$ versus $9.3 \%$ at week 26 for the intervention and comparison groups, respectively. However, the quit rates in our current study are lower than rates reported from two pilot studies with homeless smokers $[9,24]$. In one study ( $n=46)$ [9], which utilized five individual MI, six group meetings and a choice of NRT, CO-verified abstinence rates at week 26 were $17.4 \%$ versus $8.7 \%$ for intervention and comparison groups, respectively. The second study [24] $(n=58)$, which had no control group, tested the effects of a 12-week group cognitive-behavioral therapy and choice of NRT, bupropion or varenicline and reported a CO-verified quit rate of $13.6 \%$ at 24 weeks. These pilot studies had more intensive counseling interventions that may have contributed to higher quit rates. There are other reasons that could contribute to the low quit rates in our current study. In addition to multiple competing challenges that being homeless could pose to smoking cessation, our study sample had characteristics suggestive of high nicotine dependence, including factors such as smoking a pack of cigarettes per day on average, and nearly all participants smoked their first cigarette of the day within 30 minutes of awakening.

In addition, our study sample showed high rates of comorbidities with depression, alcohol and other substance abuse, with nearly 40\% having PHQ-9 scores in the moderate or worse depression range; nearly half considered themselves as alcoholic or chemically dependent. Studies in other populations have shown that these comorbidities make quitting smoking more challenging $[2,25,26]$. In essence, our study had a lower dose of counseling and higher rate of comorbidities than the two studies described above. Unlike the protocol of most smoking cessation studies in the general population, that excludes smokers with these comorbid conditions, smokers with these conditions were allowed to enroll in this study provided they were medically stable, as determined by a psychiatrist. This protocol decision was made to ensure that the study sample was similar to homeless smokers in general, which would enhance the study's external validity.

Given the challenges to smoking cessation in homeless populations, it could be argued that even these low cessation rates are probably higher than secular trends in this population and are therefore encouraging. These results highlight that homeless smokers are interested in quitting smoking and will enroll in a smoking cessation trial. Also, $75 \%$ of eligible participants returned for randomization and $75 \%$ of those enrolled completed their final week 26 visit. These results, regarding interest within homeless populations in smoking cessation, are consistent with findings from earlier studies [3,27,28]. However, these findings are in direct contrast to the presumption by some that homeless people would not be interested in smoking cessation due to many competing daily challenges, or that follow-up for longitudinal studies would be nearly impossible because of their transient housing situation.

This study also found that, contrary to expectations, MI did not improve adherence measures among participants who received MI. The lack of effect of MI to promote treatment adherence is contrary to several studies [8] that have reported large effects of MI in promoting treatment adherence. It should be noted, however, that despite not requiring motivation to quit or adhere to treatment as study enrollment criteria in the current study, participants reported high motivation to quit smoking as well as high motivation and self-efficacy to adhere to nicotine patch use. Having less favorable outcomes with MI is consistent with other studies in non-homeless settings that have shown that MI works better among people who are resistant, angry or demonstrate low motivation to change a particular health behavior [29], and therefore may be contraindicated for patients who are ready for action. Another study [30], in a non-homeless sample, found that MI was less effective than health education for smoking cessation among a sample of African American light smokers who were highly motivated to quit smoking at study enrollment.

This study has many strengths. To our knowledge, this is the largest and the first adequately powered randomized smoking cessation clinical trial in homeless populations. We successfully randomized a diverse sample of 430 homeless smokers in 15 months. We were able to achieve a study sample that is reflective of the general homeless population of the same community $[1,31]$. We also achieved $75 \%$ retention for 26 weeks. This suggests that smokers, regardless of their housing situation, want to quit and can be successful in doing so when provided with the opportunity.

This study has limitations. First, it was conducted at a single metropolitan area in the upper Midwest of the United States and there may be differences between cities, states or regions within a country and between countries that limit external validity. However, this generalizability concern is somewhat mitigated by the fact that participants were recruited from a variety of emergency shelters and transitional housing units. Data about emergency shelters from a tri-annual state-wide survey (Wilder Foundation, 2009 \# 5998) shows that the mean age for homeless people in Hennepin and Ramsey Counties encompassing the Twin Cities were 42.4 years and 42.9 years, respectively, compared to 44.4 years in our study sample. Also, our study sample was $74.7 \%$ male, which is 
comparable to that in Hennepin $(72.7 \%)$ but lower than that in Ramsey (86.5\%) Counties [31]. Secondly, because this was a treatment study, the sample was self-selected and motivated to quit smoking and thus may not be representative of homeless smokers generally. The high motivation of participants may also have made MI less effective, as MI is best suited for less motivated people $[7,30]$. However, the sample represents the group of smokers who would seek smoking cessation treatment if it were to become available in homeless populations.

Our results reveal that despite many competing daily challenges, homeless smokers are interested in smoking cessation and that motivational interviewing and nicotine replacement showed promising effects for smoking cessation for homeless populations. The low quit rate in this study calls for more studies and programs to enhance smoking cessation rates in homeless populations. It is possible that other counseling approaches, besides MI, might be more effective, or perhaps more intensive interventions are needed for smokers experiencing homelessness. Due to the high rates of psychiatric and substance abuse comorbidities in this population, will intervening in these comorbid conditions concurrently or in sequence result in improved smoking cessation rates? Because of the strikingly high prevalence of smoking and associated morbidity in homeless populations, developing and implementing programs to improve smoking cessation outcomes is critical for reducing the tobacco-related health disparities in homeless and other underserved populations.

\section{Clinical trial registration}

Trial Registration: clinicaltrials.gov: NCT00786149.

\section{Declarations of interest}

None.

\section{Acknowledgements}

The authors thank Jennifer Warren PhD and project staff Sharae Walker, Bonnie Houg, R'Gina Sellers, Casey Tuck, Abimbola Olayinka, Carolyn Borja, Carolyn Bramante, Julia Davis, Pravesh Napaul and Brandi White for their assistance with implementation of the project. The authors further acknowledge the directors of participating shelters, Dorothy Day Center, Our Savior's Shelter, Listening House, Union Gospel Mission, Naomi Family Center and People Serving People and, finally, express gratitude to the members of the $\mathrm{CAB}$ and the study participants. This work was supported by a grant from the National Heart Lung and Blood Institute [R01HL081522]. Lillian Gelberg received support from NIDA (DA022445), NCI (CA112441) and NIDDK
(DK071065). John E. Connett and Hongfei Guo received supported from the National Center for Advancing Translational Sciences of the National Institutes of Health (UL1TR000114).

\section{References}

1. Wilder Foundation. Homeless Adults and Children in Minnesota Statewide Survey. Saint Paul, MN: Wilder Foundation; 2004. Available at: http://www.wilder.org/fileadmin/ user_upload/research/Homeless2003/adult/ StatewideAdultsByMetroGreaterMN_Tables_192-199.pdf (accessed 29 September 2006) (Archived at http://www. webcitation.org/6EtqU5at5).

2. Torchalla I., Strehlau V., Okoli C. T., Li K., Schuetz C., Krausz M. Smoking and predictors of nicotine dependence in a homeless population. Nicotine Tob Res 2011; 13: 934-42.

3. Butler J., Okuyemi K. S., Jean S., Nazir N., Ahluwalia J. S., Resnicow K. Smoking characteristics of a homeless population. Subst Abuse 2002; 23: 223-31.

4. Connor J., Broad J., Rehm J., Vander Hoorn S., Jackson R. The burden of death, disease, and disability due to alcohol in New Zealand. NZ Med J 2005; 118 : U1412.

5. Teeter T. Adherence: working with homeless populations. Focus 1999; 14: 5-6.

6. el-Guebaly N., Cathcart J., Currie S., Brown D., Gloster S. Smoking cessation approaches for persons with mental illness or addictive disorders. Psychiatr Serv 2002; 53: 1166-70.

7. Hettema J. E., Hendricks P. S. Motivational interviewing for smoking cessation: a meta-analytic review. J Consult Clin Psychol 2010; 78: 868-84.

8. Hettema J., Steele J., Miller W. R. Motivational Interviewing. Annual Review of Clinical Psychology. Palo Alto, CA: Annual Reviews; 2005, p. 91-111.

9. Okuyemi K. S., Thomas J. L., Hall S., Nollen N. L., Richter K. P., Jeffries S. K. et al. Smoking cessation in homeless populations: a pilot clinical trial. Nicotine Tob Res 2006; 8: 689-99.

10. Goldade K., Whembolua G. L., Thomas J., Eischen S., Guo H., Connett J. et al. Designing a smoking cessation intervention for the unique needs of homeless persons: a communitybased randomized clinical trial. Clin Trials 2011; 8: 744-54.

11. Okuyemi K. S., Goldade K., Whembolua G. L., Thomas J. L., Eischen S., Guo H. et al. Smoking characteristics and comorbidities in the power to quit randomized clinical trial for homeless smokers. Nicotine Tob Res 2013; 15: 22-8.

12. Wilder Research Center. Homelessness in Minnesota 2003: Key Facts from Survey of Minnesotans without Permanent Housing. Saint Paul, MN: Amherst H. Foundation; 2004.

13. Sheehan D. V., Lecrubier Y., Sheehan K. H., Amorim P., Janavs J., Weiller E. et al. The Mini-International Neuropsychiatric Interview (M.I.N.I.): the development and validation of a structured diagnostic psychiatric interview for DSM-IV and ICD-10. J Clin Psychiatry 1998; 59: 22-33; quiz $4-57$.

14. Everson S. A., Goldberg D. E., Kaplan G. A., Cohen R. D., Pukkala E., Tuomilehto J. et al. Hopelessness and risk of mortality and incidence of myocardial infarction and cancer. Psychosom Med 1996; 58: 113-21.

15. Everson S. A., Kaplan G. A., Goldberg D. E., Salonen J. T. Hypertension incidence is predicted by high levels of hopelessness in Finnish men. Hypertension 2000; 35: 561-7. 
16. Etter J. F., Bergman M. M., Humair J. P., Perneger T. V. Development and validation of a scale measuring self-efficacy of current and former smokers. Addiction 2000; 95: 90113.

17. Rost K., Burnam M. A., Smith G. R. Development of screeners for depressive disorders and substance disorder history. Med Care 1993; 31: 189-200.

18. Kroenke K., Spitzer R. L., Williams J. B. The PHQ-9: validity of a brief depression severity measure. J Gen Intern Med 2001; 16: 606-13.

19. Cohen S., Kamarck T., Mermelstein R. A global measure of perceived stress. J Health Soc Behav 1983; 24: 385-96.

20. Amrhein P. C., Miller W. R., Yahne C. E., Palmer M., Fulcher L. Client commitment language during motivational interviewing predicts drug use outcomes. J Consult Clin Psychol 2003; 71: 862-78.

21. Johnson M. O., Neilands T. B., Dilworth S. E., Morin S. F., Remien R. H., Chesney M. A. The role of self-efficacy in HIV treatment adherence: validation of the HIV Treatment Adherence Self-Efficacy Scale (HIV-ASES). J Behav Med. 2007; 30: 359-70.

22. Schulz K. F., Altman D. G., Moher D., Fergusson D. CONSORT 2010 changes and testing blindness in RCTs. Lancet 2010; 375: 1144-6.

23. Okuyemi K. S., James A. S., Mayo M. S., Nollen N., Catley D., Choi W. S. et al. Pathways to health: a cluster randomized trial of nicotine gum and motivational interviewing for smoking cessation in low-income housing. Health Educ Behav 2007; 34: 43-54.
24. Shelley D., Cantrell J., Wong S., Warn D. Smoking cessation among sheltered homeless: a pilot. Am J Health Behav. 2010; 34: 544-52.

25. Sullivan M. A., Covey L. S. Current perspectives on smoking cessation among substance abusers. Curr Psychiatry Rep 2002; 4: 388-96.

26. Humfleet G., Munoz R., Sees K., Reus V., Hall S. History of alcohol or drug problems, current use of alcohol or marijuana, and success in quitting smoking. Addict Behav 1999; 24: 149-54.

27. Connor S. E., Cook R. L., Herbert M., Neal S. M., Williams J. T. Smoking cessation in a homeless population-there is a will, but is there a way? J Gen Intern Med 2002; 17: 369-72.

28. Arnsten J. H., Reid K., Bierer M., Rigotti N. Smoking behavior and interest in quitting among homeless smokers. Addict Behav 2004; 29: 1155-61.

29. Heather N., Rollnick S., Bell A., Richmond R. Effects of brief counselling among male heavy drinkers identified on general hospital wards. Drug Alcohol Rev 1996; 15: 29-38.

30. Ahluwalia J. S., Okuyemi K., Nollen N., Choi W. S., Kaur H., Pulvers K. et al. The effects of nicotine gum and counseling among African American light smokers: a $2 \times 2$ factorial design. Addiction 2006; 101: 883-91.

31. Homelessness in Minnesota. Key findings from the 2009 statewide survey [internet database]. Wilder Research. 2009. Available at: http://www.wilder.org/reportsummary. 0.html?tx_ttnews[tt_news] $=2300$ (accessed August 2010) (Archived at http://www.webcitation.org/6EtqU5at5). 